\title{
Unconventional Approaches Involving Cyclodextrin-Based, Self-Assembly-Driven Processes for the Conversion of Organic Substrates in Aqueous Biphasic Catalysis
}

\author{
Frédéric Hapiot * and Eric Monflier \\ Université Artois, CNRS, Centrale Lille, ENSCL, Université Lille, UMR 8181, \\ Unité de Catalyse et de Chimie du Solide (UCCS), F-62300 Lens, France; eric.monflier@univ-artois.fr \\ * Correspondence: frederic.hapiot@univ-artois.fr; Tel.: +33-(0)-321791773
}

Academic Editor: Luca Gonsalvi

Received: 2 May 2017; Accepted: 26 May 2017; Published: 2 June 2017

\begin{abstract}
Aqueous biphasic catalysis is a convenient approach to convert organic, partially soluble molecules in water. However, converting more hydrophobic substrates is much more challenging as their solubility in water is extremely low. During the past ten years, substantial progress has been made towards improving the contact between hydrophobic substrates and a hydrophilic transition-metal catalyst. The main cutting-edge approaches developed in the field by using cyclodextrins as a supramolecular tool will be discussed and compared in this short review.
\end{abstract}

Keywords: catalysis; cyclodextrins; supramolecular chemistry

\section{Introduction}

The 21st century has seen the emergence of new organometallic catalytic systems involving multiple components held together by weak interactions (hydrogen bonding, metal-ligand, $\pi-\pi$ stacking, electrostatic and Van der Waals interactions, and hydrophobic and solvatophobic effects). A subdiscipline of catalysis thus emerged aiming at tackling the higher complexity of catalyst design using the tools of supramolecular chemistry. This new disciplinary field is referred to as "supramolecular catalysis" [1,2]. The two key concepts underlying this discipline are molecular recognition and self-organization. Molecular recognition deals with the mutual affinity of two or more components. Enzymes proceed via molecular recognition as they fulfill multiple functions at the same time through a network of non-covalent interactions spanning from hydrogen bonds to much weaker Van der Waals forces. Additionally, they surround the substrate to force it to react in the desired manner in an organic pocket where hydrophobic forces are exerted. The term self-organization refers to a process in which the internal organization of a system, usually a non-equilibrium system, increases automatically without being directed by an external source. The spontaneous emergence of a spatial structure results from the interactions at work between elements of the system under consideration. The global properties of the obtained system are often very different from those of the individual elements.

From molecular recognition and self-organization, novel catalytic supramolecular systems have emerged. For example, the use of "host" receptors capable of supramolecularly recognizing guest molecules (substrates and/or catalyst) within their cavity showed that benefits could be gained in terms of catalyst implementation and catalytic performances (turnover, chemo- and stereoselectivities, product inhibition, etc.) [3]. Concurrently, weak interactions also proved to be effective to access novel self-assembled catalysts able to adjust their three-dimensional structure to provide good complementarity to the transition state, thus contributing to the chemo-, regio-, and stereoselectivity of 
the reaction. Most of the strategies developed so far in supramolecular catalysis have been implemented in organic solvents $[4,5]$. However, aqueous catalytic systems have also been developed. This short review is focused on cyclodextrin (CD)-based, self-assembly-driven catalytic processes taking place in water in the presence of organometallic catalysts. Emphasis is on CD-based self-assembled organometallic catalysts, micellar aggregates, and host-guest catalysis developed during the past 10 years. Through chosen examples, the role of CDs as second-sphere ligands of organometallic catalysts (and first-sphere ligands if applicable) will be discussed. Catalytic processes for which CDs are exclusively considered as first sphere ligands are not discussed herein [6,7]. The cited references are not intended to be an exhaustive list of all the works on the topic but are portals to other publications.

\section{CD-Based Organometallic Catalysts Self-Assembled via Hydrophobic Effects}

Countless novel supramolecular catalysts have been elaborated using the tools of supramolecular chemistry. Compared to the standard covalent approach, the synthesis of such catalysts was straightforward as the components self-assembled in situ during the catalytic process. Figure 1 depicts the most effective strategies developed to access self-assembled catalysts.
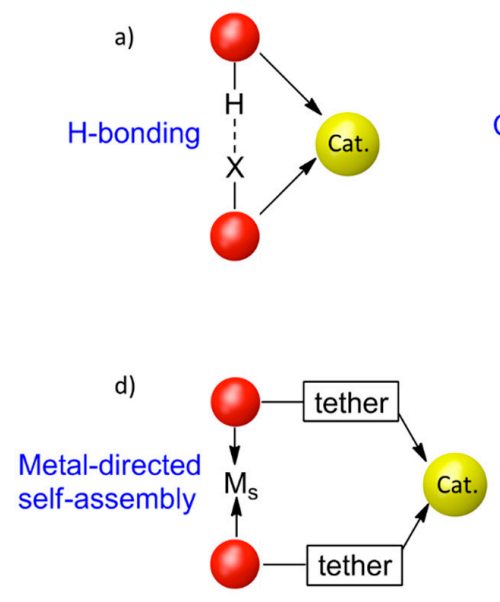
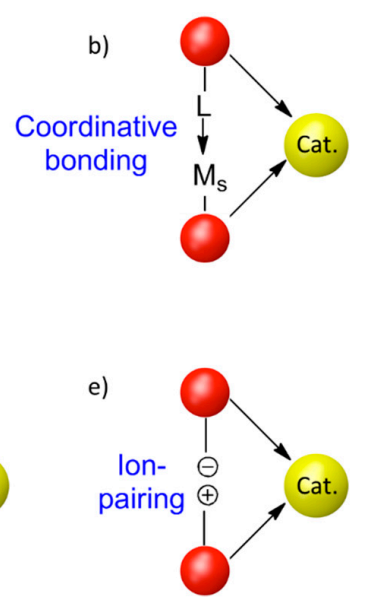

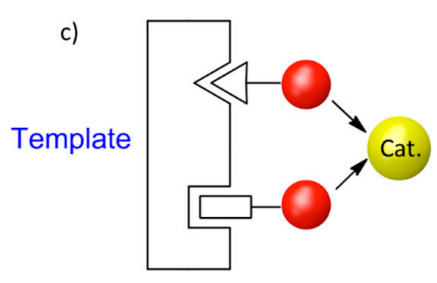

f)

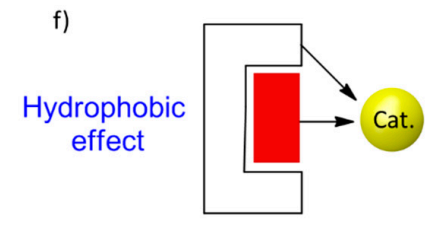

Figure 1. Strategies to elaborate supramolecular catalysts ( $\mathrm{M}_{\mathrm{S}}$ : structural metal).

Breit introduced one of the first strategies based on hydrogen bonding (Figure 1a) [8]. Concurrently, Reek and van Leeuwen developed supramolecular assemblies through coordination of bidentate ligands (Figure 1c) [9,10]. Takacs elaborated metal-directed self-assemblies (Figure 1d) [11] while Ooi developed the synthesis of ion-paired chiral ligands for organometallic catalysis (Figure 1e) [12]. In aqueous media, one of the most relevant strategy relies on hydrophobic effects (Figure 1f) [13,14]. Our group used CDs as platforms to elaborate new water-soluble bidentate ligands (Figure 2). Innovative water-soluble catalysts are obtained upon inclusion of water-soluble phosphanes in the cavity of modified $\beta$-CDs. First described in 2007 for platinum-complexes hydrogenation of water-soluble alkenes [15], the concept of supramolecular CD-based bidentate ligands was extended to the synthesis of rhodium-complexes using mono- $N, N$-dialkylamino- $\beta-C D$ derivatives and sulfonated phosphanes having a strong affinity for the $\mathrm{CD}$ cavity $\left(\mathrm{K}_{\mathrm{a}}=40,000 \mathrm{M}^{-1}\right.$ at $\left.25^{\circ} \mathrm{C}\right)$ [16]. Upon inclusion, the resulting supramolecular phosphorus-nitrogen (PN) bidentate acted as a first-sphere ligand via coordination of both a phosphane and an amine onto the metal and as a second-sphere ligand due to the inclusion of a phosphane inside the CD cavity. In hydroformylation (HF) of styrene under biphasic conditions, such Rh-PN complexes mainly yielded branched aldehydes (95\% conversion within $2 \mathrm{~h}$, branched/linear ratio up to 91/9) [17]. CD-based bidentates also acted as first- and second-sphere ligands in aqueous hydrogenation of unsaturated and allylic derivatives [18], and in a domino reaction implying nitrobenzene derivatives subjected consecutively to Pt-catalyzed reduction, Paal-Knorr cyclization and Pt-catalyzed hydrogenation [19]. 


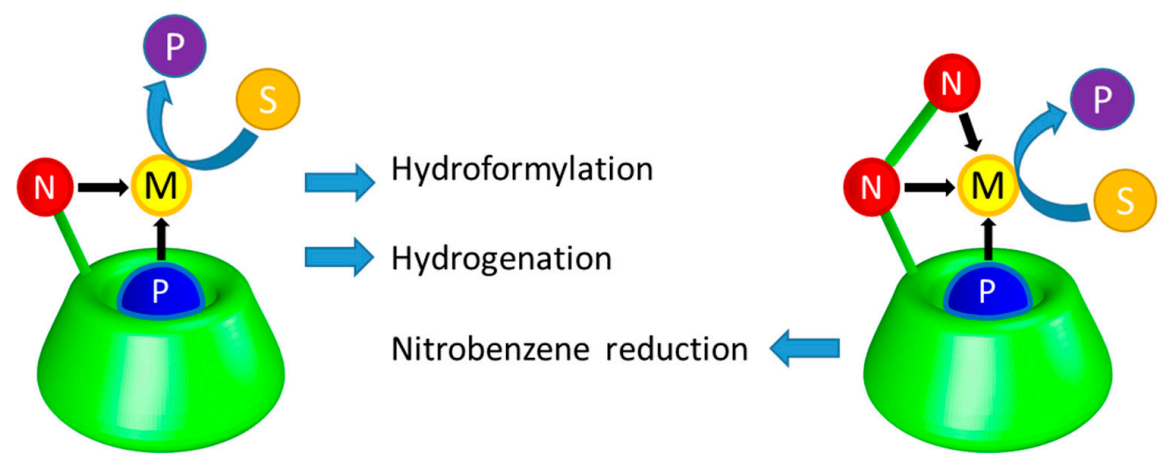

Figure 2. Supramolecular cyclodextrin (CD)-based phosphorus-nitrogen (PN) and phosphorusnitrogen-nitrogen (PNN) ligands for aqueous catalysis. M: metal; S: substrate; P: Product.

Concurrently to supramolecular systems acting as second- (and possibly first-) sphere ligands, self-assembled systems where CDs only acted as a second-sphere ligand were also developed. For example, CD dimers acted as molecular platforms capable of supramolecularly interacting with both catalyst and substrate through multiple recognition in a confined environment [20]. Compared to monotopic $\beta-C D$, the closeness of the involved entities in the surrounding of the dipotic $\beta-C D$ platform greatly enhanced both the conversion and the chemoselectivity in Rh-catalyzed HF of 1-decene. CDs also helped to convert hydrophobic substrates comprising from 8 to 12 carbons. However, the CD efficacy is significantly reduced when substrates comprising more than 12 carbons are considered. In collaboration with Gonsalvi, Peruzzini and coworkers, our group also developed new phosphanes having both surface activity and ability to coordinate to metals [21]. 1,3,5-triaza-7-phosphaadamantane (PTA) ligand was $N$-substituted by a chemical motive (para-tert-butylbenzyl) capable of interacting with the cavity of randomly methylated $\beta-C D$ (RAME- $\beta-C D$ ) (Figure 3). Contrary to the above supramolecular CD-based PN and phosphorus-nitrogen-nitrogen (PNN) ligands, the supramolecular interaction between the CD host and the PTA ligand should not be too high $\left(\mathrm{K}_{\mathrm{a}}=5440 \mathrm{M}^{-1}\right.$ at $25^{\circ} \mathrm{C}$ ) as both components should separate easily when increasing the temperature. Depending on the temperature, the amphiphilicity of the phosphane was exalted or reduced upon addition of RAME- $\beta-C D$ in water. Increasing the temperature resulted in lower CD-phosphane association and subsequent higher concentration of phosphanes in the interfacial layer. For example, in Rh-catalyzed $\mathrm{HF}$ of higher olefins, the catalytically active species mostly remained in water at $80^{\circ} \mathrm{C}$ due to inclusion of the PTA-ligand within the RAME- $\beta$-CD's cavity, thus resulting in a poor catalytic performance. Above $100^{\circ} \mathrm{C}$, the association constant between RAME- $\beta$-CD and the PTA ligand greatly decreased, resulting in higher concentrations of "free" species (non-interacting amphiphilic PTA ligand and RAME- $\beta-C D$ ). The availability of the CD cavity was enhanced and the surface activity of the ligand greatly improved, with beneficial effects on the catalytic activity. For example, $98 \%$ of 1-decene were converted within $6 \mathrm{~h}$ at $120^{\circ} \mathrm{C}$ under 50 bar of $\mathrm{CO} / \mathrm{H}_{2}$ (substrate $/ \mathrm{Rh}=500$ ). Additionally, both the aqueous and the organic phases could be simply recovered by cooling down the catalytic system. Indeed, upon cooling, the PTA-ligand accommodated the CD cavity to form a supramolecular complex, which provoked the decantation of both phases.

Adamantyl substituted compounds were also chosen as CD-interacting guests. For example, Leclercq et al. showed that methylated- $\beta$-CDs acted as second-sphere ligands of di(1-adamantyl)benzylphosphine to significantly increased the regioselectivity in homogeneous and biphasic HF of allyl alcohol and 1-octene, respectively [22]. The ability of their catalytic system to operate either under homogeneous or biphasic conditions was dictated by the hydrophobic or hydrophilic balance of the catalysts, which itself was defined by the $\beta-C D$ methylation degree. Another supramolecular complex approach was recently developed which consists in a water-insoluble palladium(II)-dipyrazole complex substituted by an adamantyl moiety [23]. Upon host-guest inclusion of the adamantyl group into the cavity of heptakis(2,6-di-O-methyl)- $\beta-\mathrm{CD}$, high catalytic 
activity were measured in Suzuki-Miyaura coupling involving hydrophilic aryl bromides and aryl boronic acids in a series of water-organic solvent mixtures. Moreover, using tetrabutyl ammonium bromide as stabilizer, the catalyst was recycled and reused several times. Following a similar approach, a water-soluble glutathione peroxidase mimic was constructed based on the supramolecular host-guest interaction existing between the mono-amino- $\beta-C D$ and a tellurium compound substituted by two adamantyl groups [24]. The supramolecular system formed hollow vesicle-like aggregates in water, which exhibited enzyme-like catalytic activity and specific recognition ability in the reduction of cumene hydroperoxide by 3-carboxyl-4-nitrobenzenethiol.

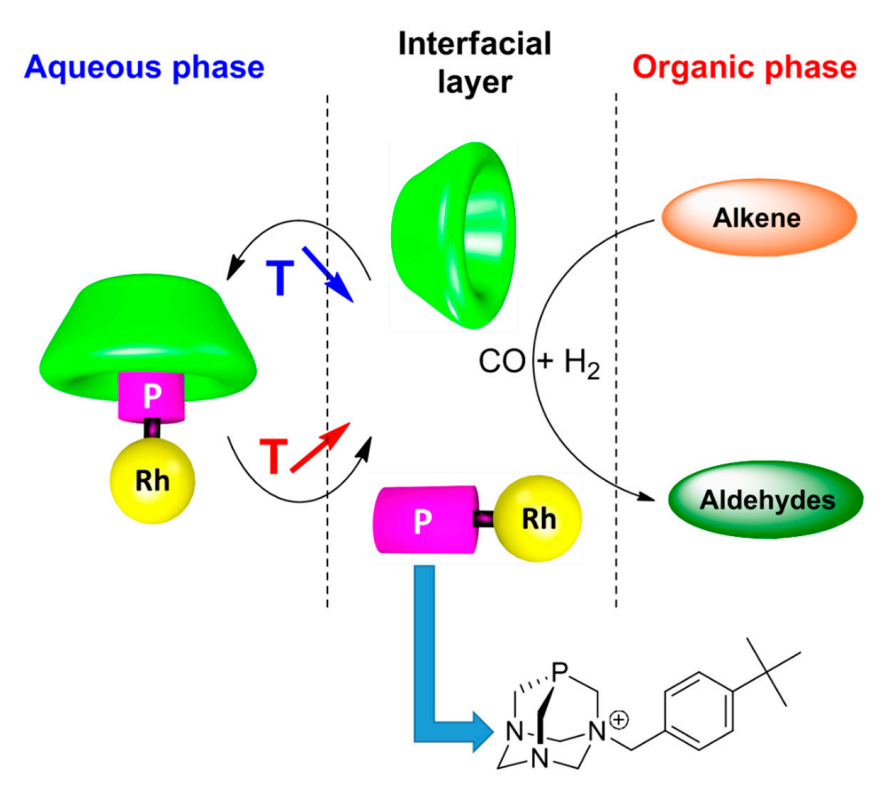

Figure 3. Thermocontrolled catalysis using randomly methylated $\beta-C D$ (RAME- $\beta-C D)$ and appropriate phosphane.

\section{Control of Micelle Dynamics}

Micelles are surfactant-based nano-aggregates acting as nanoreactors by virtue of the confinement of substrates and/or catalyst inside their self-assembled structure [25]. The catalytic performance was significantly improved as the local concentrations in catalyst and substrates were significantly increased at the micelle interface. For example, $\mathrm{CDs}$ and imidazolium surfactants were combined to promote the formation of micelles in thermoregulated Rh-catalyzed HF of alkenes [26]. More precisely, the alkyl chain of surfactants such as $\left[\mathrm{C}_{12} \mathrm{MIM}\right][\mathrm{X}]$ and $\left[\mathrm{C}_{16} \mathrm{MIM}\right][\mathrm{X}]\left(\mathrm{X}=\mathrm{Br}\right.$ or TfO) included into the $\alpha-\mathrm{CD}^{\prime} \mathrm{s}$ cavity at room temperature while both components dissociated at $80^{\circ} \mathrm{C}$ to trigger self-aggregation of imidazolium salts into micelles. In Rh-catalyzed HF of allyl aromatics or styrene, such micelles hosted the substrate into their core while the Rh concentration increased at the micelle surface upon interaction of the imidazolium with the rhodium catalyst, resulting in enhanced conversions $(100 \%$ conversion at $80{ }^{\circ} \mathrm{C}$ under 50 bar of $\mathrm{CO} / \mathrm{H}_{2}$ ). Upon cooling down the solution once the reaction was complete, the inclusion of the imidazolium alkyl chain into the $\alpha$-CD's cavity provoked the destabilization of the micelles. Through temperature control, the catalytic performance was improved and the rhodium catalyst was recovered.

Grafting dodecyl-imidazolium onto $\beta$-CDs was also an effective strategy to access supramolecular hosts capable of self-assembling in neat water [27]. The catalytic properties of the resulting micelles were assessed in Suzuki-Miyaura reaction implying aryl halides and boronic acid derivatives. Interestingly, the dodecyl-imidazolium CD-based micelles allowed converting sterically hindered substrates having strong hydrophobic character into hetero coupling products. Additionally, the system was recycled more than 10 times without significant loss of catalytic activity. 
Our group developed the synthesis of amphiphilic phosphanes featuring both surface-activity and ability to coordinate to metal precursors. To overcome the formation of stable emulsions resulting from mixtures of amphiphilic molecules, water and organic substrate, we made use of modified $\beta$-CDs. We especially found that addition of stoichiometric proportions of ionic $\beta$-CD into amphiphilic phosphane-containing micellar solutions unexpectedly improved the performances of Rh-catalyzed HF of 1-decene while addition of neutral $\beta$-CDs resulted in the destructuring of micelles in the post-micellar concentration range [28]. Using ionic $\beta$-CDs, an average fourfold rise in catalytic activity was measured ( $65 \%$ conversion of 1-decene within $6 \mathrm{~h}$ under 50 bar of $\mathrm{CO} / \mathrm{H}_{2}$ at $80^{\circ} \mathrm{C}$, substrate $/ \mathrm{Rh}=260$ ) without any influence on the regioselectivity (linear/branched ratio up to 8.6). In that case, complementary properties of the ligand and the surfactant were expressed in a single material. Additionally, the main advantage of the ionic $\beta$-CD-based catalytic system relied on the recovery of the aqueous and organic phases once the reaction was complete, especially if randomly methylated $\beta$-CD (RAME- $\beta$-CD) was used as additives. Amphiphilic phosphane-based aggregates also acted as substrate reservoir in a palladium-catalyzed Tsuji-Trost reaction [29]. The presence of RAME- $\beta$-CD in the aqueous compartment improved dynamics of phosphane-based aggregates by supramolecular means (Figure 4). Exchanges between the hydrophobic aggregate core (which contained the substrate) and the aqueous phase (which contained the Pd-catalyst) were significantly favored. Accordingly, the catalytic performance was boosted in a narrow concentration range. RAME- $\beta-C D$ acted as fluidifier of the phosphane-based micelles. Note that the catalytic performances are dependent on the strength of the supramolecular interaction between the phosphane and the CD. For $\mathrm{K}_{\mathrm{a}}$ values over $200,000 \mathrm{M}^{-1}$, high turn-over frequencies (TOF) are measured for 1:1 RAME- $\beta-\mathrm{CD} /$ phosphane ratio as the aggregate dynamics are favored. Increasing the RAME- $\beta-C D /$ phosphane ratio results in the formation of stable RAME- $\beta-C D /$ phosphane complexes. Micelles are then destructured, resulting in a lower TOF. Conversely, weak $K_{a}$ values $\left(300-600 \mathrm{M}^{-1}\right)$ lead to a lower amplitude between the highest and the lowest TOF.
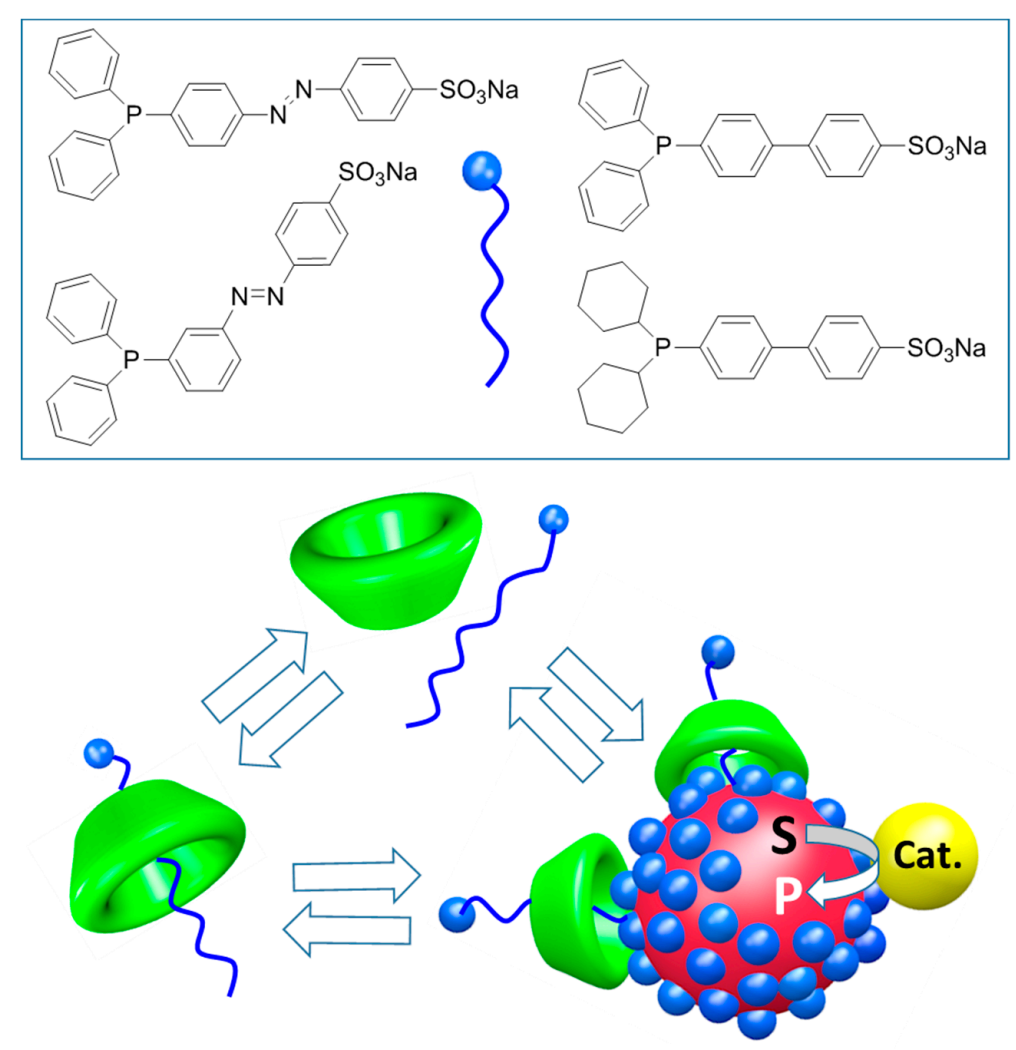

Figure 4. Dynamics of exchange between the hydrophobic micelle core and the aqueous compartment in the presence of RAME- $\beta$-CD. S: substrate; P: product; C: organometallic catalyst. 


\section{Self-Emulsifying Catalytic System}

We recently implemented a novel catalytic system involving $\mathrm{CD} /$ substrate supramolecular interactions. More precisely, naturally occurring triglycerides were hydroformylated through supramolecular means in the presence of CDs in aqueous medium. During the course of the reaction, a transient supramolecular complex was formed in a well-defined concentration range between triglyceride alkyl chains and CRYSMEB, a methylated $\beta$-CD substituted on C2 hydroxyl groups (Figure 5). The triglyceride/water interface was then greatly extended, thus favoring contacts between the triolein carbon-carbon double bond and the rhodium catalyst. In fact, upon inclusion of its alkenyl chain into the $\mathrm{CD}$ cavity, the substrate drove its own transformation as the resulting $\mathrm{CD}$ /triglyceride supramolecular complexes acted as emulsifiers and helped to convert the triglyceride $\mathrm{C}=\mathrm{C}$ double bonds in biphasic conditions using a water-soluble organometallic catalyst. At the end of the reaction, the low affinity between the hydroformylated products and CRYSMEB triggered the decantation of products and catalytic solution. The catalytic system was recycled and successfully extended to rhodium-catalyzed HF of commercial oils.

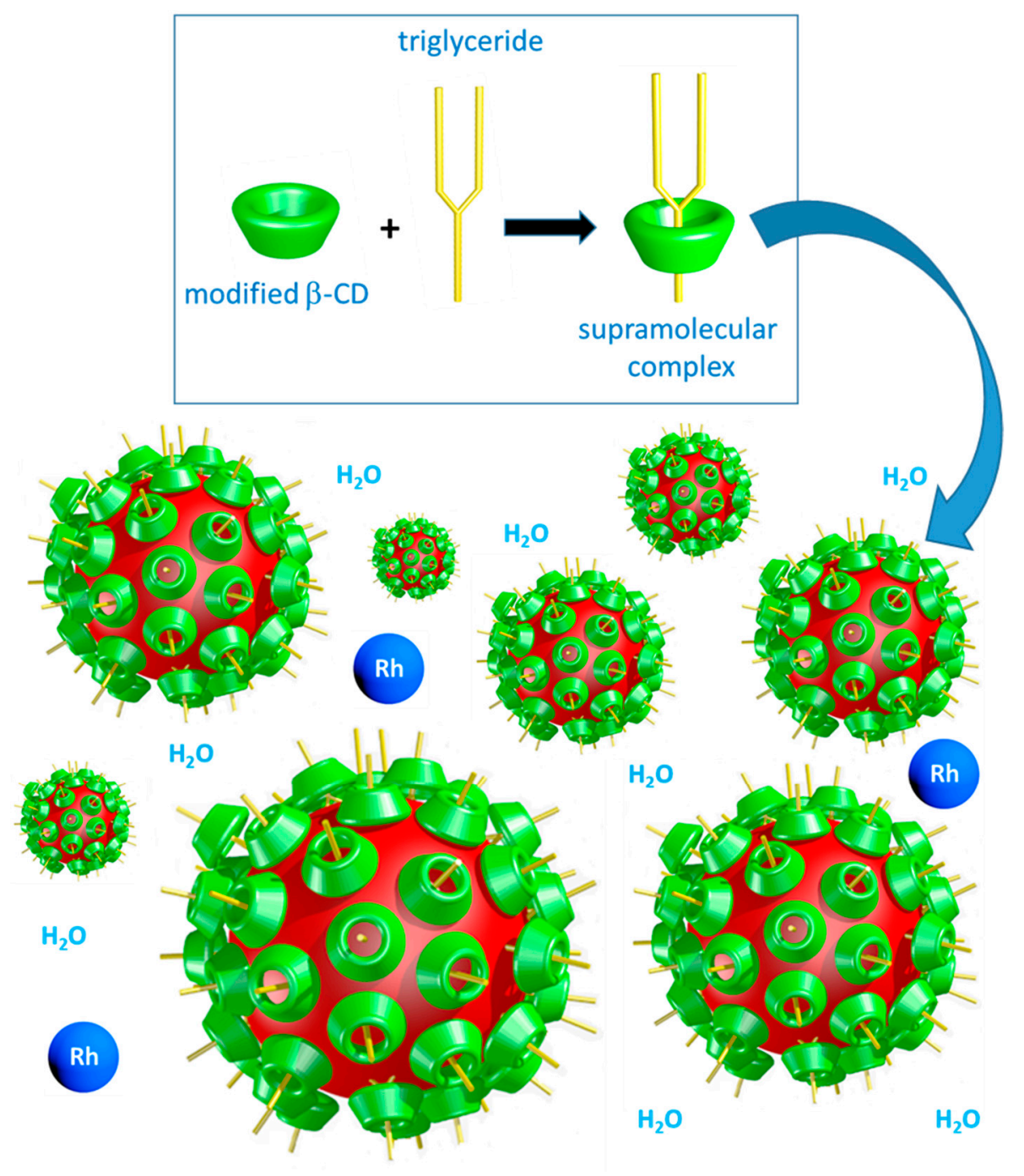

Figure 5. Triglyceride droplets stabilized in water by modified CDs.

\subsection{CD-Based Pickering-Like Emulsions}

Another approach involving CD-based polymers relies on a thermoresponsive poly( $N$-isopropylacrylamide) (PNIPAM) substituted at its end with RAME- $\beta$-CD (Figure 6) [30]. 
The lower critical solution temperature (LCST) of the resulting modified PNIPAM was $36.6{ }^{\circ} \mathrm{C}$ (transition between hydrophilic and hydrophobic state). Its average molecular weight was $16,000 \mathrm{~g} \mathrm{~mol}^{-1}(\mathrm{D}=1.38)$ and its hydrodynamic radius was $368 \mathrm{~nm}$ at $80{ }^{\circ} \mathrm{C}$. A coil-to-globule transition took place above the LCST, with the formation of micrometer-sized aggregates. In rhodium catalyzed $\mathrm{HF}$ of 1-decene and 1-hexadecene, the CD-substituted polymer appeared to be more effective than the separated PNIPAM and RAME- $\beta$-CD components. It was shown that RAME- $\beta$-CD-based polymer aggregates formed a Pickering-like emulsion (emulsion stabilized by particle) upon adsorption at the aqueous/organic interface. Over time, the aggregates covered the interface to such an extent that the mass transfer was greatly reduced. To overcome the issue, we applied successive heating/cooling cycles to recover the interface fluidity. Cooling down the system below the LCST induced disassembly of the polymer particles. The polymer chains then regained their fluidity and water solubility. The vanishing of the Pickering-like emulsion resulted in the rapid decantation of the biphasic system. Reheating the mixture over the LCST regenerated the Pickering-like emulsion. Complete HF of 1-decene and 1-hexadecene could be implemented through the above step-by-step process.

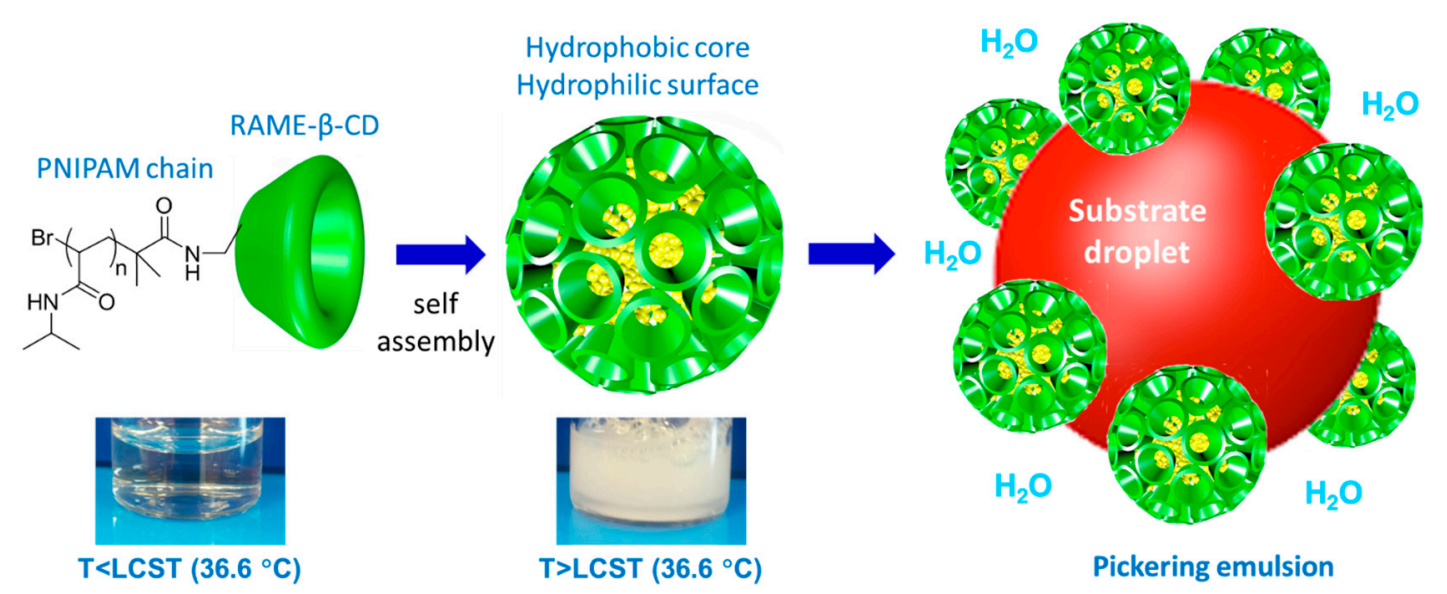

Figure 6. Formation of Pickering emulsion from thermoresponsive poly( $N$-isopropylacrylamide) (PNIPAM) functionalized at the terminal position with RAME- $\beta-C D$.

Supramolecular hydrogels consist of three-dimensional networks with non-covalent bonds. They were recently considered as aqueous media likely to contain organometallic catalysts. Interestingly, supramolecular hydrogels consisting of CD-based pseudo-polyrotaxanes resulted from the threading of $\alpha$-CDs along poly(ethylene glycol) (PEG) chains. Upon threading, $\alpha$-CDs align to form columnar domains, which subsequently arrange into nanocrystallites. In the presence of an organic phase, the nanocrystallites' adsorption at the water-oil interface resulted in Pickering-like emulsions (Figure 7). For example, the catalytic performance in Rh-catalyzed HF of 1-decene in the sol phase was significantly improved in the presence of $\alpha$-CD/PEG nanocrystallites (PEG molecular weights of 20,000 g. $\mathrm{mol}^{-1}$ (PEG20000) or 35,000 $\mathrm{g} \cdot \mathrm{mol}^{-1}$ (PEG35000)) [31]. As observed previously, an interface saturation occurred over time. The saturation phenomenon was easily overcome by cooling down the system below the sol-gel temperature and partially depressurizing the autoclave. The Pickering emulsion being broken, dynamics of exchange within the interfacial layer were then greatly improved. Upon temperature and pressure changes, the carbon-carbon double bonds were fully hydroformylated. Addition of RAME- $\beta-C D$ in well-defined proportion into the hydrogel also substantially improved both the catalytic activity and chemoselectivity [32]. RAME- $\beta-C D$ also acted as fluidifier of the Pickering-like emulsion and prevented the interface saturation. Dynamics of exchange at the interface were greatly accelerated. 


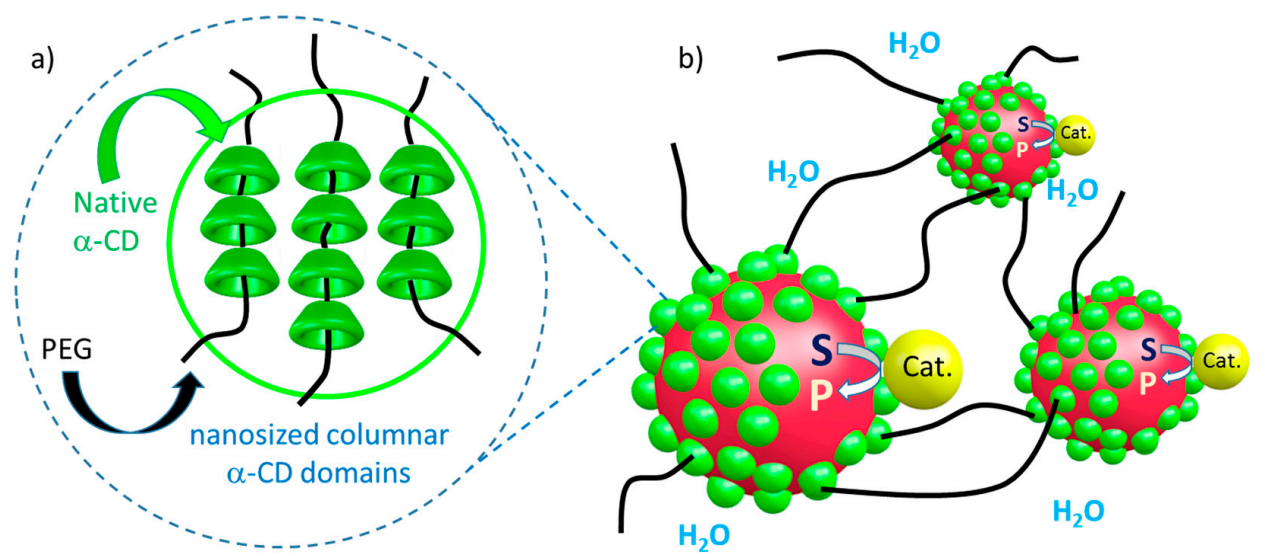

Figure 7. Interfacial catalysis in emulsion using CD/poly(ethylene glycol) (PEG) combination: (a) supramolecular hydrogel consisting of nanocrystallites; (b) stabilization of substrate droplets in the hydrogel phase via oil-in-water Pickering emulsion. S, substrate; P, product; C, aqueous organometallic catalyst.

\subsection{Multivalency with $C D$ Dimers and $C D$ Polymers}

Multivalency is a powerful self-assembly pathway that confers unique molecular recognition between polytopic hosts and guests [33,34]. Large hosts with extended cavities are then highly desirable to fully accommodate hydrophobic substrates through multivalency. CD dimers interact more strongly with linear substrates than simple CD receptors owing to their multiple interactions and binding properties. Additionally, the spacer linking the $\beta-C D$ together supplies additional binding towards the guest molecule upon inclusion complexation. Such cooperative effects were powerful enough to favor the mass transfer in aqueous catalytic systems. RAME- $\beta$-CD dimers synthesized by $\mathrm{Cu}(\mathrm{I})$-catalyzed azide-alkyne cycloaddition (CuAAC) proved to be very effective in the Pd-catalyzed Tsuji-Trost reaction [35]. The 'extended' cavity accommodated hydrophobic substrates that were too long to be recognized into a single CD cavity.

Multivalent CD-based polymers were also used as interfacial additives in Rh-catalyzed HF of long-alkyl-chain alkenes (Figure 8) [36]. RAME- $\beta-C D-\mathrm{NH}_{2}$ was grafted to size-controlled poly(N-acryloyloxysuccinimide) (polyNAS) to give water-soluble CD-based polymers $\left(800 \mathrm{~g} \cdot \mathrm{L}^{-1}\right.$ at $\left.20^{\circ} \mathrm{C}\right)$ with surface activity $\left(50-60 \mathrm{mN} \cdot \mathrm{m}^{-1}\right)$. Their catalytic performance was assessed in $\mathrm{Rh}$-catalyzed HF of 1-decene and 1-hexadecene. While RAME- $\beta$-CD allowed converting 1-decene, polyNAS highly substituted by RAME- $\beta$-CD proved to be more efficient than RAME- $\beta$-CD to favor the conversion of 1-hexadecene through multivalent interactions. Two close CDs substantially favored the molecular recognition of 1-hexadecene. The local concentration of the latter was significantly increased at the interface, thus favoring contacts with the water soluble rhodium catalyst.

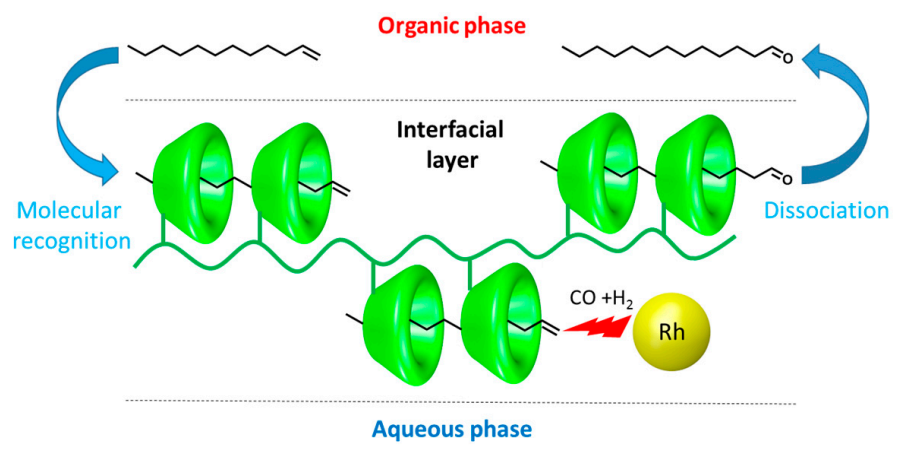

Figure 8. Hydroformylation (HF) of long alkyl chain alkenes using CD-based polymers. 
The multivalency concept was then further extended to CD-grafted polyNAS (degree of polymerization of 45) functionalized with the water-soluble sulfonated 2-(diphenylphosphino)ethanamine [37]. The remaining succinimide functions reacted with aminoethanol to give trisubstituted water soluble polymers. Such polymers benefited from both the supramolecular properties of CDs and the capability of phosphanes to coordinate organometallic species. In comparison with sulfonated 2-(diphenylphosphino)ethanamine, the phosphane-grafted, CD-grafted polyNAS gave better activities and aldehyde selectivity in rhodium catalyzed $\mathrm{HF}$ of 1-hexadecene at $80{ }^{\circ} \mathrm{C}$ under 50 bar of $\mathrm{CO} / \mathrm{H}_{2}$ pressure. As the $\mathrm{CD}$-included substrate and the catalyst were very close, the reaction took place rapidly. For example, 1-hexadecene was fully converted within only $1 \mathrm{~h}$ using a 2:1 CD-to-phosphane ratio.

\section{Conclusions}

Cyclodextrin-based, self-assembly-driven processes have provided compelling evidence that they are powerful tools to improve the catalytic performance of organometallic reactions under biphasic conditions. Such self-assembly-driven processes open fascinating opportunities in the area of organometallic catalysis. The art of self-assembling CDs and ligands, substrates, or other components of the catalytic system promotes both activity and selectivities through molecular recognition and self-organization. The role of CDs in such systems is manifold. They favor contacts between the substrate and the catalyst, modify the aqueous/organic interface, or control the second-sphere of the metal with beneficial effect on the catalytic activity and the selectivities of the reaction. Moreover, CD-based, self-assembly-driven processes appear to be a relevant approach as a rapid screening of the catalytic system can be implemented by just mixing the different components. In this context, we anticipate that CD-based self-assemblies will be used increasingly in the near future to develop more active and more selective catalytic systems. While we still have a long way to fully define the potential of CD-based self-assemblies, the authors hoped this review will inspire the reader to imagine novel approaches involving CD-based, self-assembly-driven processes.

Acknowledgments: The University of Artois is acknowledged for supporting and partially funding this work. Chevreul Institute (FR 2638), Ministère de l'Enseignement Supérieur et de la Recherche, Région Nord-Pas de Calais and FEDER are acknowledged for supporting and funding partially this work.

Author Contributions: F.H. and E.M. wrote the paper equally.

Conflicts of Interest: The authors declare no conflict of interest.

\section{References}

1. Raynal, M.; Ballester, P.; Vidal-Ferrana, A.; van Leeuwen, P.W. Supramolecular catalysis. Part 1: Non-covalent interactions as a tool for building and modifying homogeneous catalysts. Chem. Soc. Rev. 2014, 43, 1660-1733. [CrossRef] [PubMed]

2. Ballester, P.; Vidal-Ferrana, A. Supramolecular Catalysis; van Leeuwen, P.W., Ed.; Wiley-VCH: Weinheim, Germany, 2008; pp. 1-27.

3. Catti, L.; Zhang, Q.; Tiefenbacher, K. Advantages of catalysis in self-assembled molecular capsules. Chem. Eur. J. 2016, 22, 9060-9066. [CrossRef] [PubMed]

4. Leenders, S.H.; Gramage-Doria, R.; de Bruin, B.; Reek, J.N. Transition metal catalysis in confined spaces. Chem. Soc. Rev. 2015, 44, 433-448. [CrossRef] [PubMed]

5. Bocokić, V.; Kalkan, A.; Lutz, M.; Spek, A.L.; Gryko, D.T.; Reek, J.N. Capsule-controlled selectivity of a rhodium hydroformylation catalyst. Nat. Commun. 2013, 4, 2670. [CrossRef] [PubMed]

6. Jouffroy, M.; Armspach, D.; Matt, D. Cyclodextrin and phosphorus(III): A versatile combination for coordination chemistry and catalysis. Dalton Trans. 2015, 44, 12942-12969. [CrossRef] [PubMed]

7. Zaborova, E.; Deschamp, J.; Guieu, S.; Blériot, Y.; Poli, G.; Ménand, M.; Madec, D.; Prestat, G.; Sollogoub, M. Cavitand supported tetraphosphine: Cyclodextrin offers a useful platform for Suzuki-Miyaura cross-coupling. Chem. Commun. 2011, 47, 9206-9208. [CrossRef] [PubMed]

8. Chevallier, F.; Breit, B. Self-assembled bidentate ligands for Ru-catalyzed anti-Markovnikov hydration of terminal alkynes. Angew. Chem. Int. Ed. 2006, 45, 1599-1602. [CrossRef] [PubMed] 
9. Kuil, M.; Goudriaan, P.E.; Tooke, D.M.; Spek, A.L.; van Leeuwen, P.W.; Reek, J.N. Rigid bis-zinc(II) salphen building blocks for the formation of template-assisted bidentate ligands and their application in catalysis. Dalton Trans. 2007, 2311-2320. [CrossRef] [PubMed]

10. Pignataro, L.; Lynikaite, B.; Cvengro, J.; Marchini, M.; Piarulli, U.; Gennari, C. Combinations of acidic and basic monodentate binaphtholic phosphites as supramolecular bidentate ligands for enantioselective Rh-catalyzed hydrogenations. Eur. J. Org. Chem. 2009, 2539-2547. [CrossRef]

11. Moteki, S.A.; Takacs, J.M. Exploiting self-assembly for ligand-scaffold optimization: Substrate-tailored ligands for efficient catalytic asymmetric hydroboration. Angew. Chem. Int. Ed. 2008, 47, 894-897. [CrossRef] [PubMed]

12. Ohmatsu, K.; Ito, M.; Kunieda, T.; Ooi, T. Ion-paired chiral ligands for asymmetric palladium catalysis. Nat. Chem. 2012, 4, 473-477. [CrossRef] [PubMed]

13. Biedermann, F.; Nau, W.M.; Schneider, H.-J. The hydrophobic effect revisited—Studies with supramolecular complexes imply high-energy water as a noncovalent driving force. Angew. Chem. Int. Ed. 2014, 53, 11158-11171. [CrossRef] [PubMed]

14. Kataev, E.A.; Müller, C. Recent advances in molecular recognition in water: Artificial receptors and supramolecular catalysis. Tetrahedron 2014, 70, 137-167. [CrossRef]

15. Machut, C.; Patrigeon, J.; Tilloy, S.; Bricout, H.; Hapiot, F.; Monflier, E. Self-assembled supramolecular bidentate ligands for aqueous organometallic catalysis. Angew. Chem. Int. Ed. 2007, 46, 3040-3042. [CrossRef] [PubMed]

16. Patrigeon, J.; Hapiot, F.; Canipelle, M.; Menuel, S.; Monflier, E. Cyclodextrin-based supramolecular $P, N$ bidentate ligands and their platinum and rhodium complexes. Organometallics 2010, 29, 6668-6674. [CrossRef]

17. Hapiot, F.; Bricout, H.; Tilloy, S.; Monflier, E. Functionalized cyclodextrins as first and second coordination sphere ligands for aqueous organometallic catalysis. Eur. J. Inorg. Chem. 2012, 1571-1578. [CrossRef]

18. Potier, J.; Guerriero, A.; Menuel, S.; Monflier, E.; Peruzzini, M.; Hapiot, F.; Gonsalvi, L. Cyclodextrins as first and second sphere ligands for $\mathrm{Rh}(\mathrm{I})$ complexes of lower-rim PTA derivatives for use as catalysts in aqueous phase hydrogenation. Catal. Commun. 2015, 63, 74-78. [CrossRef]

19. Menuel, S.; Bertaut, E.; Monflier, E.; Hapiot, F. Cyclodextrin-based PNN supramolecular assemblies: A new class of pincer-type ligands for aqueous organometallic catalysis. Dalton Trans. 2015, 44, 13504-13512. [CrossRef] [PubMed]

20. Blaszkiewicz, C.; Bricout, H.; Léonard, E.; Len, C.; Landy, D.; Cézard, C.; Djedaïni-Pilard, F.; Monflier, E.; Tilloy, S.A. Cyclodextrin dimer as a supramolecular reaction platform for aqueous organometallic catalysis. Chem. Commun. 2013, 49, 6989-6991. [CrossRef] [PubMed]

21. Six, N.; Guerriero, A.; Landy, D.; Peruzzini, M.; Gonsalvi, L.; Hapiot, F.; Monflier, E. Supramolecularly controlled surface activity of an amphiphilic ligand. Application to aqueous biphasic hydroformylation of higher olefins. Catal. Sci. Technol. 2011, 1, 1347-1353. [CrossRef]

22. Leclercq, L.; Schmitzer, A.R. Assembly of tunable supramolecular organometallic catalysts with cyclodextrins. Organometallics 2010, 29, 3442-3449. [CrossRef]

23. Qi, M.; Tan, P.Z.; Xue, F.; Malhi, H.S.; Zhang, Z.-X.; Young, D.J.; Hor, T.S.A. A supramolecular recyclable catalyst for aqueous Suzuki-Miyaura coupling. RSC Adv. 2015, 5, 3590-3596. [CrossRef]

24. Yin, Y.; Jiao, S.; Zhang, R.; Wang, X.; Zhang, L.; Yang, L. Construction of a soluble supramolecular glutathione peroxidase mimic based on host-guest interaction. Curr. Organocatal. 2015, 2, 64-70. [CrossRef]

25. La Sorella, G.; Strukul, G.; Scarso, A. Recent advances in catalysis in micellar media. Green Chem. 2015, 17, 644-683. [CrossRef]

26. Leclercq, L.; Lacour, M.; Sanon, S.H.; Schmitzer, A.R. Thermoregulated microemulsions by cyclodextrin sequestration: A new approach to efficient catalyst recovery. Chem. Eur. J. 2009, 15, 6327-6331. [CrossRef] [PubMed]

27. Kairouz, V.; Schmitzer, A.R. Imidazolium-functionalized $\beta$-cyclodextrin as a highly recyclable multifunctional ligand in water. Green Chem. 2014, 16, 3117-3124. [CrossRef]

28. Ferreira, M.; Bricout, H.; Azaroual, N.; Landy, D.; Tilloy, S.; Hapiot, F.; Monflier, E. Cyclodextrin/amphiphilic phosphane mixed systems and their applications in aqueous organometallic catalysis. Adv. Synth. Catal. 2012, 354, 1337-1346. [CrossRef] 
29. Bricout, H.; Léonard, E.; Len, C.; Landy, D.; Hapiot, F.; Monflier, E. Impact of cyclodextrins on the behavior of amphiphilic ligands in aqueous organometallic catalysis. Beilstein J. Org. Chem. 2012, 8, 1479-1484. [CrossRef] [PubMed]

30. Potier, J.; Menuel, S.; Lyskawa, J.; Fournier, D.; Stoffelbach, F.; Monflier, E.; Woisel, P.; Hapiot, F. Thermoresponsive self-assembled cyclodextrin-end-decorated PNIPAM for aqueous catalysis. Chem. Commun. 2015, 51, 2328-2330. [CrossRef] [PubMed]

31. Potier, J.; Menuel, S.; Chambrier, M.-H.; Burylo, L.; Blach, J.-F.; Woisel, P.; Monflier, E.; Hapiot, F. Pickering emulsions based on supramolecular hydrogels: Application to higher olefins' hydroformylation. ACS Catal. 2013, 3, 1618-1621. [CrossRef]

32. Potier, J.; Menuel, S.; Monflier, E.; Hapiot, F. Synergetic effect of randomly methylated $\beta$-cyclodextrin and a supramolecular hydrogel in Rh-catalyzed hydroformylation of higher olefins. ACS Catal. 2014, 4, 2342-2346. [CrossRef]

33. Barnard, A.; Smith, D.K. Self-assembled multivalency: Dynamic ligand arrays for high-affinity binding. Angew. Chem. Int. Ed. 2012, 51, 6572-6581. [CrossRef] [PubMed]

34. Mulder, A.; Huskens, J.; Reinhoudt, D.N. Multivalency in supramolecular chemistry and nanofabrication. Org. Biomol. Chem. 2004, 7, 3409-3424. [CrossRef] [PubMed]

35. Six, N.; Menuel, S.; Bricout, H.; Hapiot, F.; Monflier, E. Ditopic cyclodextrin-based receptors: New perspectives in aqueous organometallic catalysis. Adv. Synth. Catal. 2010, 352, 1467-1475. [CrossRef]

36. Potier, J.; Menuel, S.; Fournier, D.; Fourmentin, S.; Woisel, P.; Hapiot, F.; Monflier, E. Cooperativity in aqueous organometallic catalysis: Contribution of cyclodextrin-substituted polymers. ACS Catal. 2012, 2, 1417. [CrossRef]

37. Potier, J.; Menuel, S.; Mathiron, D.; Bonnet, V.; Hapiot, F.; Monflier, E. Cyclodextrin-grafted polymers functionalized with phosphanes: A new tool for aqueous organometallic catalysis. Beilstein J. Org. Chem. 2014, 10, 2642-2648. [CrossRef] [PubMed]

(C) 2017 by the authors. Licensee MDPI, Basel, Switzerland. This article is an open access article distributed under the terms and conditions of the Creative Commons Attribution (CC BY) license (http:/ / creativecommons.org/licenses/by/4.0/). 